\title{
Frequency of unexpected red blood cell antibodies in Nanjing
}

\author{
Haishi Qiao, Jiling Xu, Jie Cai, Yuting Lu, Yonglin Yang*, Qiang Fu* \\ Nanjing Red Cross Blood Center, Nanjing, Jiangsu 210003, China
}

\begin{abstract}
The development of unexpected red blood cell antibodies can significantly complicate transfusion therapy and result in more difficulties in cross-matching of blood. This study aimed to determine the occurrence rate of red blood cell alloimmunization in patients from Nanjing and the surrounding area. The antibody screening tests were carried out on 604 patients in Nanjing Red Cross Blood Center from January 2014 to December 2016, and the results were compiled and statistically analyzed. In the 604 patients, 483 cases revealed autoantibodies with or without underlying alloantibodies, while 121 patients had only alloantibodies in their serum. The overall frequency of alloimmunization was $32.5 \%$. The most frequent antibodies were what against the Rh systerm(72.39\%), followed by $\mathrm{MN}$ system $(25.71 \%)$.
\end{abstract}

Keywords: incidence, autoantibody, alloantibody, alloimmunization

\section{INTRODUCTION}

All redblood cell antibodies other than naturally occurred anti-A and anti-B antibodies are defined as "unexpected antibodies" including autoantibody and alloantibody ${ }^{[1]}$. An autoantibody is an antibody produced by the immune system that is directed against one or more of the individual's own proteins. Many autoimmune diseases (notably lupus erythematosus) are caused by such autoantibodies ${ }^{[2]}$. Production of alloantibodies may result from exposure to foreign antigens such as pregnancy, transfusion, transplantation, or injections of immunogenic material ${ }^{[3]}$. These antibodies can cause acute and delayed hemolytic transfusion reactions and there are many reports on such cases $^{[4]}$. Therefore, it is important to conduct testing to screen and identify the unexpected antibodies before transfusion.

*Correspondence to: Qiang Fu, MD, Nanjing Red Cross Blood Center, Nanjing, Jiangsu 210003, China. TEL: 86-25-83476663; FAX:86-2583476663; E-mail: qiangfu@163.com; Yonglin Yang, MD, Nanjing Red Cross Blood Center, Nanjing, Jiangsu 210003, China. TEL: 8625-83476663, FAX:86-25-83476663, E-mail: easing@163.com.
The occurrence of red blood cell(RBC) alloantibodies has been reported in a variety of studies, and usually correlated with a previous history of transfusion or pregnancy, human leukocyte antigen (HLA)DR typing, immune status and RBC density among people of different ethnical groups ${ }^{[5]}$. RBC alloantibodies have been detected in up to $0.8 \%$ of blood donors, and in $1 \%-2 \%$ of hospitalized patients. The occurrence of unexpected antibodies is approximately $2 \%-9 \%$ in patients with a history of blood transfusion and 9\%-30\% in patients with chronic transfusion therapy ${ }^{[6]}$. It is generally known that there are large differences in the frequency and type of unexpected antibodies found during screening according to the research subjects, blood type, genotypic frequency, screening method, and ability of the decoder ${ }^{[7]}$. The frequency of unexpected antibodies is reported to be $1.35 \%$ in Denmark ${ }^{[8]}, 0.78 \%$ in Germany ${ }^{[9]}$, and $0.3 \%-$ $2.0 \%$ in the $\mathrm{USA}^{[10]}$. The frequency and type of unexpected antibodies in Nanjing has not been studied.

It is essential to know the frequency and distribution of unexpected antibodies among China for prompt and safe blood transfusion. The purpose of this study was to examine the frequency and type of unexpected 
antibodies by antibody screening and identification in patients of Nanjing Red Cross Blood Center (NRCBC) from 2014 to 2016.

\section{MATERIALS AND METHODS}

\section{Study population}

The samples that showed positive results of antibody screening test before blood transfusion or clinical difficulties in blood cross-matching were included in this study. All samples came from transfusion candidates in hospital of Nanjing and surrounding area.

\section{Antibody screening and identification}

Antibody screening and identification were done using gel column assay (Boxun, Changchun, China) or tube test. A commercially available three cell panel (Shanghai Blood Biological Medical Co., LTD, Shanghai, China) was used for antibody screening procedure in which the subject's plasma was reacted with a panel of red cells. The cards were incubated at $37^{\circ} \mathrm{C}$ for 15 minutes and then centrifuged for 5 minutes. The serum samples which were positive on the antibody screening were conducted with antibody identification. An extended 10-cell panel was used for antibody identification (Shanghai Blood Biological Medical Co., LTD, Shanghai, China). The serum of patients was reacted with the 10-cell panel of red cells and the cards were incubated at $37{ }^{\circ} \mathrm{C}$ for 15 minutes and then centrifuged for 5 minutes. The antigens on $\mathrm{RBC}$ were also determined by tube test to confirm the results of antibody identification.

\section{RESULTS}

\section{Frequency of unexpected antibodies}

The frequencies of unexpected antibodies in 604 cases delivered to NRCBC were identified. The number of patients with each type of antibody was shown in Table 1. There were $408(67.5 \%)$ of them with autoantibodies, $121(20.0 \%)$ with alloantibodies, and 75(12.5\%) cases had both autoantibodies and alloantibodies. The number of patients with autoantibodies was significantly higher than those with alloantibodies.

\section{Type and distribution of unexpected antibodies}

The identification tests for typing the unexpected

Table 1 Autoantibody and alloantibody detected in patients

\begin{tabular}{lc}
\hline Antibody & Case $/ n(\%)$ \\
\hline Autoantibody only & $408(67.5)$ \\
Alloantibody only & $121(20.0)$ \\
Autoantibody and alloantibody & $75(12.5)$ \\
\hline
\end{tabular}

antibody were conducted in the 196 patients with alloantibodies. The results showed that $\mathrm{Rh}$ antibody had the highest frequency (72.39\%), followed by MN system antibody (25.71\%). The frequencies of Rh antibodies were $38.10 \%$ for anti-cE, $21.90 \%$ for anti-E, $2.86 \%$ for anti-Ce, and $0.95 \%$ for anti-c. Anti-D and anti-C shared the same percentage which is $4.29 \%$. Only anti-M antibodies (25.71\%) were found in the MN system, however, it was the second most common antibody besides anti-cE(Table 2).

Table 2 The type and frequency of alloantibody

\begin{tabular}{lcc}
\hline System & Antibody specificity & Case/n(\%) \\
\hline $\mathrm{Rh}$ & Anti-cE & $80(38.10)$ \\
& Anti-E & $46(21.90)$ \\
& Anti-Ce & $6(2.86)$ \\
& Anti-c & $2(0.95)$ \\
& Anti-C & $9(4.29)$ \\
& Anti-D & $9(4.29)$ \\
$\mathrm{MN}$ & Anti-M & $54(25.71)$ \\
Lewis & Anti-Le & $2(0.95)$ \\
Kidd & Anti-Jk $^{\mathrm{a}}$ & $1(0.48)$ \\
$\mathrm{Pl}$ & Anti-P1 $^{\mathrm{a}}$ & $1(0.48)$ \\
\hline
\end{tabular}

\section{Characteristics of patients with unexpected antibodies}

In these 604 patients with positive unexpected antibodies, $318(52.65 \%)$ were female and $286(47.35 \%)$ were male. The distributions of both autoantibody and alloantibody between male and female were significantly different. As shown in Table 3, the frequency of autoantibodies in the male group (86.62\%) was significantly higher than that in the female group (61.64\%). However, the distribution of alloantibodie spresented an opposite tendency, which was higher among the females. The percentage of female in 182 patients with positive alloantibodies was $76.92 \%$.

Table 3 Gender characteristics of patients with unexpected antibodies

\begin{tabular}{lccc}
\hline Gender & Case $/ n(\%)$ & Autoantibody $/ n(\%)$ & Alloantibody $/ n(\%)$ \\
\hline Male & $286(47.35)$ & $272(86.62)$ & $42(13.38)$ \\
Female & $318(52.65)$ & $225(61.64)$ & $140(38.36)$ \\
\hline
\end{tabular}

The age distribution in patients with unexpected antibodies was as follows: $\leqslant 30 \mathrm{yr}, 114$ (18.87\%); $31-60 \mathrm{yr}, 174(28.81 \%) ; \geqslant 61 \mathrm{yr}, 316(52.32 \%)$. As shown in Table 4, the frequencies of autoantibody increased while alloantibody decreased with age gradually. The percentage of elderly people $(\geqslant 61 \mathrm{yr})$ in patients with autoantibody was $61.12 \%$.

As shown in Table 5, the ABO blood group distribution in patients with unexpected antibodies was as follows: A, 208 (34.44\%); B, $164(27.15 \%)$; AB, 77 (12.75\%); O, 155 (25.66\%). The frequencies of either autoantibody or alloantibody showed no differ- 
ence among patients of $\mathrm{A}, \mathrm{B}$ and $\mathrm{O}$ type. However, the frequencyof autoantibody in $\mathrm{AB}$ type was lower and alloantibody was higher than other blood types significantly (Table 5).

Table 4 Age characteristics of patients with unexpected antibodies

\begin{tabular}{cccc}
\hline Age $(\mathrm{yr})$ & Case $/ n(\%)$ & Autoantibody $/ n(\%)$ & Alloantibody $/ n(\%)$ \\
\hline$\leqslant 30$ & $114(18.87)$ & $67(51.94)$ & $62(48.06)$ \\
$31-60$ & $174(28.81)$ & $127(64.80)$ & $69(35.20)$ \\
$\geqslant 61$ & $316(52.32)$ & $305(86.16)$ & $49(13.84)$ \\
\hline
\end{tabular}

Table 5 Blood group characteristics of patients with unexpected antibodies

\begin{tabular}{cccc}
\hline Blood Group & Case $/ n(\%)$ & Autoantibody $/ n(\%)$ & Alloantibody $/ n(\%)$ \\
\hline A & $208(34.44)$ & $174(76.32)$ & $54(23.68)$ \\
B & $164(27.15)$ & $130(75.14)$ & $43(24.86)$ \\
AB & $77(12.75)$ & $57(61.29)$ & $36(38.71)$ \\
O & $155(25.66)$ & $138(74.59)$ & $47(25.41)$ \\
\hline
\end{tabular}

\section{DISCUSSION}

Regular antibodies were usually referred to the isohemagglutinins and were directed against antigens of the ABO system ${ }^{[11]}$. It is not certain whether they are natural antibodies or caused by infection in early life. The irregular antibody is a different kind of blood group antibody from the anti-A, anti-B antibody ${ }^{[12]}$. In China, irregular antibody screening methods use a standard series of red blood cells ${ }^{[2,5]}$. With red blood cells containing the corresponding antigen and $\operatorname{IgM}$ antibody in a saline medium, visible condensation occurs (traditional $\mathrm{ABO}$ grouping); $\mathrm{IgG}$ antibodies with the corresponding cell reaction are analyzed by means of an enzymatic test or antiglobulin test to visible condensation $^{[13]}$.

Elevated frequencies of transfusion reaction have been reported, about one percent of all transfusions developed antibodies that may eventually lead to the reaction $^{[6,14]}$. Some of the reactions may occur as a result of irregular antibody production including a delayed hemolytic reaction, which happened when the antibodies attack antigens (other than $\mathrm{ABO}$ antigens) on the transfused blood cells slowly. The blood cells would break down by days or weeks after the transfusion ${ }^{[7,15]}$.

In this study, we demonstrated that the frequency of autoantibody $(80.0 \%)$ is higher than that of alloantibody (32.5\%), which is different from previous reports. This may be due to the high proportion of elderly patients in the study population. And our study also showed the frequency of autoantibody increased, while alloantibody decreased gradually with age.

The analysis of alloantibody showed that Rh antibody had the highest frequency $(72.39 \%)$, followed by MNS antibody $(25.71 \%)$; and the incidence rate of alloantibody in female (38.36\%) was significantly higher than that in male (13.38\%). Interestingly, we also found the frequency of alloantibody in $\mathrm{AB}$ blood type significantly different from other blood types.

Our study still has some limitations such as lacking clinical data, including ethnic group, pregnancy history, transfusion history which may influence the occurrence rate of unexpected antibodies.

\section{References}

[1] Shirey RS, Boyd JS, Parwani AV, et al. Prophylactic antigen-matched donor blood for patients with warm autoantibodies: an algorithm for transfusion management[J]. Transfusion, 2002,42: 1435-41.

[2] Shin JH, Lee JY, Kim JH, et al. Screening and identification of unexpected red cell antibodies by simultaneous LISS/Coombs and NaCl/Enzyme gel methods[J]. J Korean Med Sci, 2009,24: 632-5.

[3] Natukunda B, Schonewille H, van de Watering L, et al. Prevalence and specificities of red blood cell alloantibodies in transfused Ugandans with different diseases[J]. Vox Sang, 2010,98: 167-71.

[4] Schonewille H, Brand A. Does an alloimmune response to strong immunogenic red blood cell antigens enhance a response to weaker antigens?[J]. Transfusion, 2008,48: 958-63.

[5] Cheng CK, Lee CK, Lin CK. Clinically significant red blood cell antibodies in chronically transfused patients: a survey of Chinese thalassemia major patients and literature review[J]. Transfusion, 2012,52: 2220-4.

[6] Caamano J, Musante E, Contreras M, et al. Frequency and specificity of red blood cell alloimmunization in chilean transfused patients[J]. Transfus Med Hemother, 2015,42: 4-7.

[7] Eipl K, Nakabiito C, Bwogi K, et al. Seroprevalence of unexpected red blood cell antibodies among pregnant women in Uganda[J]. Immunohematology, 2012,28: $115-7$.

[8] Skov F, Eriksen M, Hagerup L. Distribution of the ABO, MNS, P, Rhesus, Lutheran, Kell, Lewis and Duffy blood groups and frequency of irregular red cell antibodies in a population of Danes aged fifty years and a population of Danes aged seventy years. From the Glostrup population studies[J]. Acta Pathol Microbiol Scand B Microbiol Immunol, 1970,78: 553-9.

[9] Spielmann W, Seidl S. Prevalence of irregular red cell antibodies and their significance in blood transfusion and antenatal care[J]. Vox Sang, 1974,26: 551-9.

[10] Boral LI, Henry JB. The type and screen: a safe alternative and supplement in selected surgical procedures[J]. Transfusion, 1977,17: 163-8.

[11] Thakral B, Saluja K, Sharma RR, et al. Red cell alloimmunization in a transfused patient population: a study from a tertiary care hospital in north India[J]. Hematology, 2008,13: 313-8.

[12] Ngoma AM, Mutombo PB, Ikeda K, et al. Red blood 
cell alloimmunization in transfused patients in sub-Saharan Africa: A systematic review and meta-analysis[J]. Transfus Apher Sci, 2016,54: 296-302.

[13] Eichler H, Bohler A, Hastka J, et al. Micro-column affinity test and gel test: comparative study of two techniques for red cell antibody screening[J]. Vox Sang, 1999,77: 154-8.

[14] Cohen D, Hartung H, Evans P, et al. Red blood cell al- loimmunization in transfused patients with bone marrow failure syndromes[J]. Transfusion, 2016,56: 1314-9.

[15] Makroo RN, Bhatia A, Hegde V, et al. Antibody screening \& identification in the general patient population at a tertiary care hospital in New Delhi, India[J]. Indian J Med Res, 2014,140: 401-5.

(Received 2 May 2017, Revised 18 May 2017, Accepted 30 May 2017) 